\title{
Structural Transformations and Mechanical Properties of Metastable Austenitic Steel under High Temperature Thermomechanical Treatment
}

\author{
Igor Litovchenko*(D), Sergey Akkuzin $\mathbb{D}^{\mathrm{D}}$, Nadezhda Polekhina, Kseniya Almaeva and Evgeny Moskvichev $\mathbb{1 0}$ \\ Institute of Strength Physics and Materials Science of the Siberian Branch of the Russian Academy of \\ Sciences (ISPMS SB RAS), 2/4 pr. Akademicheskii, 634055 Tomsk, Russia; akkuzin.spti@mail.ru (S.A.); \\ nadejda89tsk@yandex.ru (N.P.); kseni_ya_almaeva@mail.ru (K.A.); em_tsu@mail.ru (E.M.) \\ * Correspondence: litovchenko@spti.tsu.ru; Tel.: +7-913-824-16-94
}

check for updates

Citation: Litovchenko, I.; Akkuzin S.; Polekhina, N.; Almaeva, K.; Moskvichev, E. Structural Transformations and Mechanical Properties of Metastable Austenitic Steel under High Temperature Thermomechanical Treatment. Metals 2021, 11, 645. https://doi.org/ $10.3390 /$ met11040645

Academic Editors: Francesca Borgioli and C. Isaac Garcia

Received: 10 March 2021

Accepted: 13 April 2021

Published: 15 April 2021

Publisher's Note: MDPI stays neutral with regard to jurisdictional claims in published maps and institutional affiliations.

Copyright: (c) 2021 by the authors. Licensee MDPI, Basel, Switzerland. This article is an open access article distributed under the terms and conditions of the Creative Commons Attribution (CC BY) license (https:// creativecommons.org/licenses/by/ $4.0 /)$.

\begin{abstract}
The effect of high-temperature thermomechanical treatment on the structural transformations and mechanical properties of metastable austenitic steel of the AISI 321 type is investigated. The features of the grain and defect microstructure of steel were studied by scanning electron microscopy with electron back-scatter diffraction (SEM EBSD) and transmission electron microscopy (TEM). It is shown that in the initial state after solution treatment the average grain size is $18 \mu \mathrm{m}$. A high $(\approx 50 \%)$ fraction of twin boundaries (annealing twins) was found. In the course of hot (with heating up to $1100^{\circ} \mathrm{C}$ ) plastic deformation by rolling to moderate strain $(e=1.6$, where $e$ is true strain) the grain structure undergoes fragmentation, which gives rise to grain refining (the average grain size is $8 \mu \mathrm{m}$ ). Partial recovery and recrystallization also occur. The fraction of low-angle misorientation boundaries increases up to $\approx 46 \%$, and that of twin boundaries decreases to $\approx 25 \%$, compared to the initial state. The yield strength after this treatment reaches up to $477 \mathrm{MPa}$ with elongation-to-failure of $26 \%$. The combination of plastic deformation with heating up to $1100{ }^{\circ} \mathrm{C}(e=0.8)$ and subsequent deformation with heating up to $600^{\circ} \mathrm{C}(e=0.7)$ reduces the average grain size to $1.4 \mu \mathrm{m}$ and forms submicrocrystalline fragments. The fraction of low-angle misorientation boundaries is $\approx 60 \%$, and that of twin boundaries is $\approx 3 \%$. The structural states formed after this treatment provide an increase in the strength properties of steel (yield strength reaches up to $677 \mathrm{MPa}$ ) with ductility values of $12 \%$. The mechanisms of plastic deformation and strengthening of metastable austenitic steel under the above high-temperature thermomechanical treatments are discussed.
\end{abstract}

Keywords: metastable austenitic steel; high temperature thermomechanical treatment; electron microscopy; deformation microstructures; grain refinement; mechanical properties

\section{Introduction}

Austenitic steels are widely used in many industries, but their application is still limited by relatively low strength properties (yield strength of 200-340 MPa) in the initial (quenched or solution treated) state [1-3]. The mechanical properties of these steels are successfully improved relative to the initial values by plastic deformation and (or) by thermomechanical treatments [4-6]. Under conditions of cold plastic deformation in metastable austenitic steels, dislocation gliding is not the only deformation mechanism of plastic deformation; there are also strain-induced $\gamma \rightarrow \varepsilon$ (face-center-cubic (fcc) $\rightarrow$ hexagonal-closed-packed (hcp)) and $\gamma \rightarrow \varepsilon \rightarrow \alpha^{\prime}$ (fcc $\rightarrow$ hcp $\rightarrow$ body-center-cubic (bcc)) martensitic transformations [1,2,5,7-11]. In austenitic steels with low stacking fault (SF) energy under these conditions, a high density of microtwin packets is formed [12-15]. It is shown that with increasing deformation degree the microstructure of 304-type steel progressively changes: Dislocations (Ds) $\rightarrow$ Ds $+\mathrm{SFs}+\varepsilon \rightarrow \mathrm{Ds}+\mathrm{SFs}+\mathrm{Twins}+\varepsilon \rightarrow \mathrm{Ds}$ + SFs + Twins $+\varepsilon+\alpha^{\prime} \rightarrow$ Ds + Twins $+\alpha^{\prime}$ [16]. The heterophase submicrocrystalline structure of metastable austenitic steel represented by deformation $\alpha^{\prime}$-martensite packets 
with a high dislocation density and austenite microtwins, provides a significant increase in strength (yield strength of more than $1000 \mathrm{MPa}$ ) relative to the initial state. This markedly reduces the plastic properties of the material $[15,17]$. It should also be noted that as a result of the formation of $\alpha^{\prime}$-martensite, steel becomes magnetic [18], which might limit its practical application. Under annealing after cold deformation, reverse transformations of martensitic phases into austenite, recovery and recrystallization of austenite occur. In this case, the plastic properties increase, but the full completion of the reverse transformations with the formation of $100 \%$ austenite leads to a significant decrease in strength, compared to the cold-deformed state [19-21].

Under hot and warm plastic deformation of austenitic steels, less deformed structural states are formed, compared to the cold deformation [22-25]. This is due to the lack of conditions for the martensitic transformations and mechanical twinning and to the effects of dynamic recovery and recrystallization. The stacking faults energy increases with increasing temperature [26,27], so high stresses are required to split perfect dislocations to partial dislocations, which prevents deformation twinning. The ductility after such treatments is significantly higher while the strength properties are lower, compared to those at similar degrees of low temperature deformation. To achieve high-strength states (yield strength more than $1000 \mathrm{MPa}$ ), severe plastic deformations are required [28]. A combination of high degrees of deformation and temperature-strain rate treatment modes can activate the processes of dynamic recrystallization. In this case, an equiaxed submicrocrystalline structure is formed. This structure contains a combination of grains with an increased dislocation density and low-defect grains $[23,28,29]$.

Extensive investigations of the effect of thermomechanical control processing on the grain structure and mechanical properties of austenitic steels have been performed [30-33] and recrystallization of type 321 steel during and after hot deformation was studied [34,35]. It was shown that for the formation of a recrystallized structure, deformation should be carried out in the temperature range of $900-1200{ }^{\circ} \mathrm{C}$. The recrystallization temperature depends on the elemental composition of the steels. The reduction in the austenite grain size is achieved by lowering the rolling end temperature, increasing the cooling rate, and by increasing the cooling start temperature in the recrystallization region [31]. In this case, low values of hardening are achieved (the yield point does not exceed $300 \mathrm{MPa}$ ). Deformation at lower temperatures leads to the formation of a pancake structure and localization of deformation [30]. In this case, the values of the yield strength are generally higher than $400 \mathrm{MPa}$ with a corresponding loss of ductility.

Despite the extensive research into the effect of warm deformation on the microstructure and mechanical properties of austenitic steels, the effect of deformation in the recrystallization region followed by deformation at lower temperatures remains unclear. Type 321 steel is relatively little studied compared to other austenitic steels such as 304 and 316 . The presence of titanium in the solid solution of 321 steel can lead to rapid precipitation of dispersed $\mathrm{Ti}(\mathrm{C}, \mathrm{N})$ particles during warm deformation in the temperature range of $750-800{ }^{\circ} \mathrm{C}$ [36]. Deformation at 800 and $850{ }^{\circ} \mathrm{C}$ is accompanied by the formation of $\mathrm{M}_{23} \mathrm{C}_{6}$ precipitates at the grain boundaries of austenite [37].

In this work, we focus on the microstructure features and their impact on the strength and plastic properties of metastable AISI 321 austenitic steel after hot deformation and a combination of hot and warm deformations at moderate deformation degrees.

\section{Materials and Methods}

The material used was Russian grade (08Kh18N10T) austenitic chromium-nickel steel (AISI 321 type) Fe-18.02Cr-9.77Ni-1.4Mn-0.59Ti-0.39Si-0.19Cu-0.1Mo-0.08C (mass.\%). Prior to deformation, the samples were solution treated (ST) at $1100{ }^{\circ} \mathrm{C}$ for $1 \mathrm{~h}$ followed by water quenching. The initial sample size was $\approx 50 \times 12 \times 10 \mathrm{~mm}^{3}$. Thermomechanical treatments were performed in two modes. The first treatment consisted of hot (with heating up to $1100{ }^{\circ} \mathrm{C}$ ) rolling deformation in 3 passes with a total degree of deformation $e=1.6$, where $e$ is true strain. Heating was carried out in a tubular electric furnace of the T-40/600 type 
(Russia). The temperature was determined by the furnace thermocouple. Before the first pass, the sample was kept in the furnace for $1 \mathrm{~h}$ to align the chemical composition, similar to ST. Before the second and third passes, the samples were kept in the furnace for 10 and $5 \mathrm{~min}$, respectively, to align the temperature to the sample. After removal from the mill the samples were quenched in water after each pass. The rolling mill was maintained at room temperature. The strain rate was $\sim 1 \mathrm{~s}^{-1}$. This treatment is termed as high-temperature thermo-mechanical treatment-1 (HTMT-1). The second treatment consisted of hot rolling deformation with heating up to $1100{ }^{\circ} \mathrm{C}, e=0.8$ in one pass, and subsequent deformation with heating up to $600^{\circ} \mathrm{C}, e=0.7$ in one pass (HTMT-2). As in the first case, after each pass the samples were quenched in water.

The time before the transfer of the sample from the furnace to the rolling mill was 5-10 s, so the actual deformation temperature was lower than the temperature in the furnace. The first treatment and the first stage of the second treatment were performed with heating above the recrystallization start temperature. The deformation temperature in the second stage of the second treatment is lower than the recrystallization temperature. It is chosen low enough to significantly increase the strength of the material and prevent the intensive precipitation of dispersed particles during warm deformation. This significantly increases the load on the rolling mill.

The microstructural characterization was performed using a Tescan MIRA 3 LMU scanning electron microscope (SEM) equipped with a field emission gun (FEG) and an Oxford Instruments Nordlys F electron back-scattered diffraction (EBSD) detector. The SEM samples were prepared by mechanical polishing followed by ion milling as a final polishing step. Ion polishing was performed using a Technoorg Linda SEMPrep 2 system. The EBSD data were obtained with step sizes of $500 \mathrm{~nm}$ (ST), $300 \mathrm{~nm}$ (HTMT-1), and $100 \mathrm{~nm}$ (HTMT-2). After deformation treatments, the EBSD images were taken perpendicular to the rolling plane. The microstructure and texture analyses were carried out by the Oxford Instruments AZtec software. It is assumed in this paper that the average grain size corresponds to the equivalent circle diameter obtained from EBSD data. The high angle boundaries are the boundaries with a misorientation angle of $>15^{\circ}$; only these boundaries are taken into account when estimating the average grain size.

Transmission electron microscopy (TEM) investigations were conducted using a Philips CM-12 electron microscope at an accelerating voltage of $120 \mathrm{kV}$. Thin foils were prepared from sections perpendicular to the rolling plane by electropolishing in an electrolyte containing $450 \mathrm{~mL}$ of orthophosphoric acid and $50 \mathrm{~g}$ of chromic anhydride. The dislocation density was estimated by the linear intercept method [38].

Mechanical tests were carried out at ambient temperature by the method of static tensile deformation at a strain rate of $\approx 2 \times 10^{-3} \mathrm{~s}^{-1}$ on a NIKIMT 1246R-2/2300 hightemperature vacuum testing machine (Russia) using dog-bone samples with the gage length of $13 \mathrm{~mm}$ and gage section of $2 \times 1 \mathrm{~mm}^{2}$. Samples were cut parallel to the rolling plane. The scheme of microstructure observation and cutting of samples for tension tests is presented in Supplementary Materials Figure S1.

\section{Results}

\subsection{EBSD Study}

The results of EBSD studies and their statistical analysis are presented in Figures 1-3 and in Supplementary Materials Figure S2. 


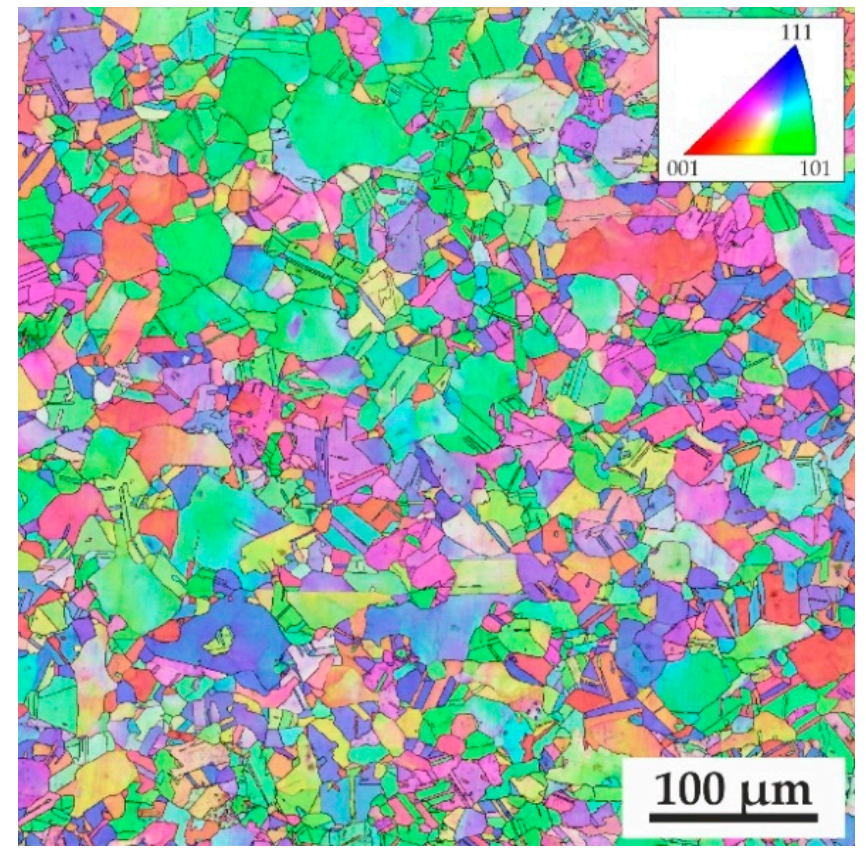

(a)

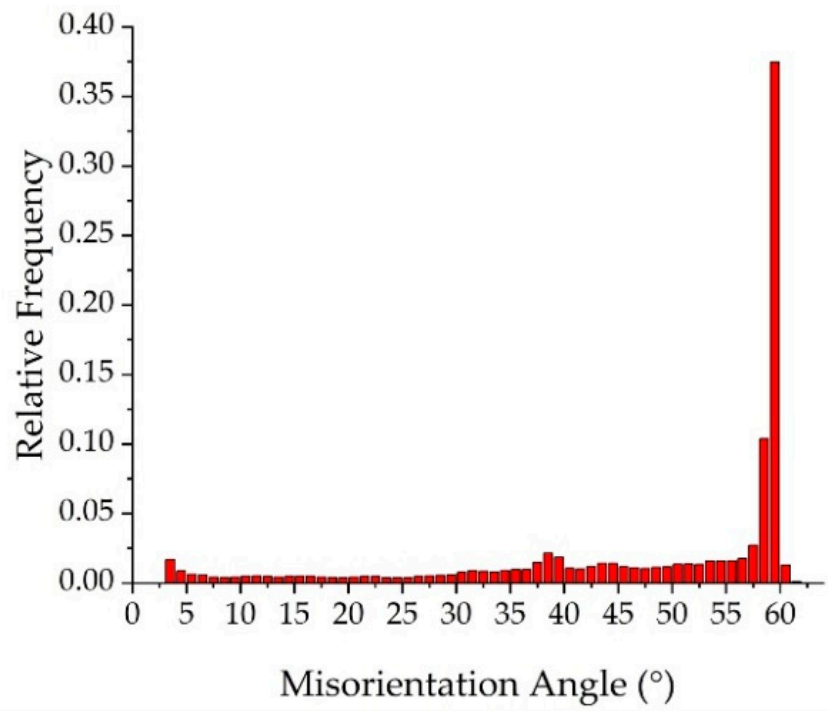

(b)

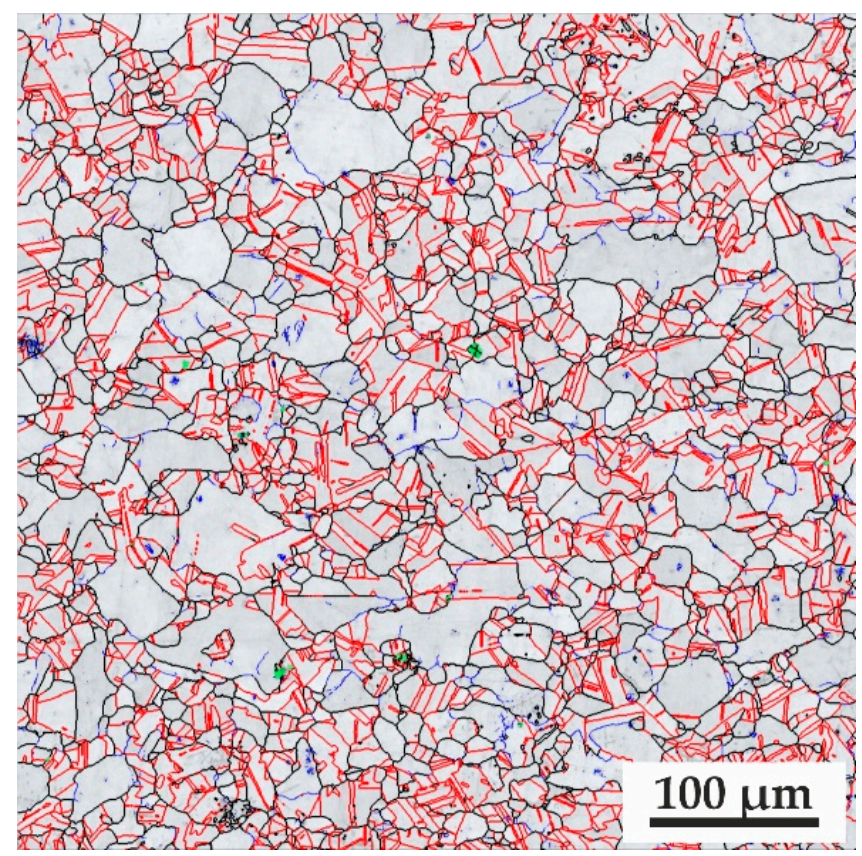

(c)

Figure 1. Electron back-scattered diffraction (EBSD) images of the initial steel microstructure. Orientation maps (a), grain misorientation distribution (b), phase maps, where TiC is in green color, austenite is in gray color with high-, low-angle, and twin boundaries are denoted by black, blue, and red lines, respectively (c). In other figures, the same boundary coloring is used. 


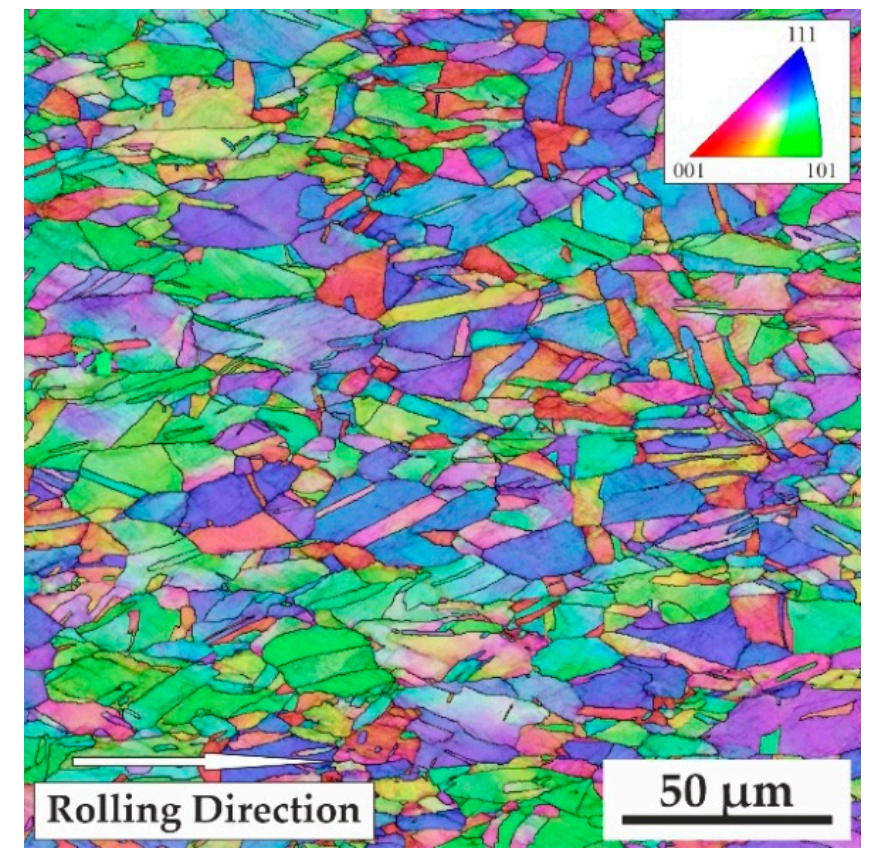

(a)

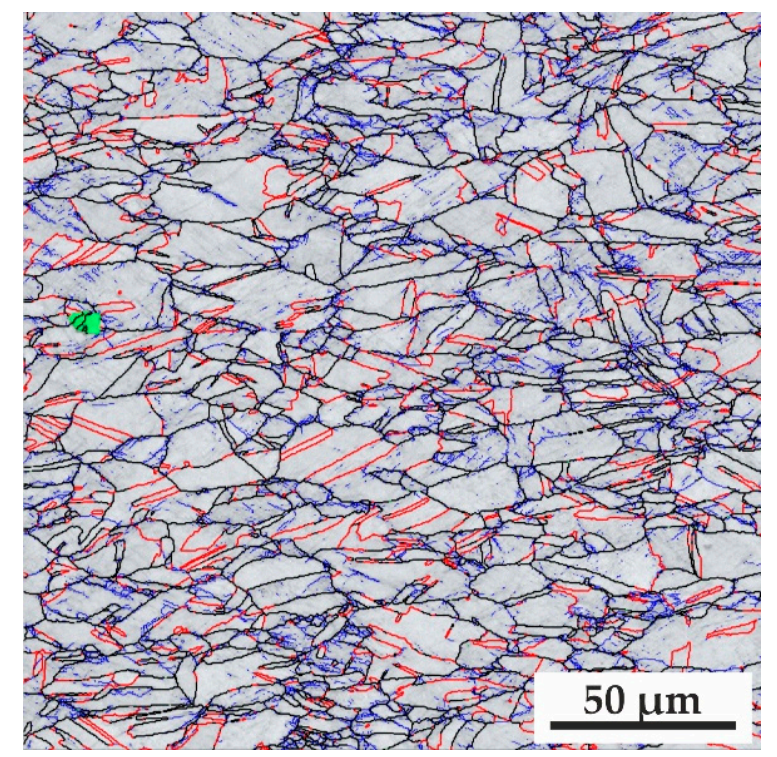

(c)

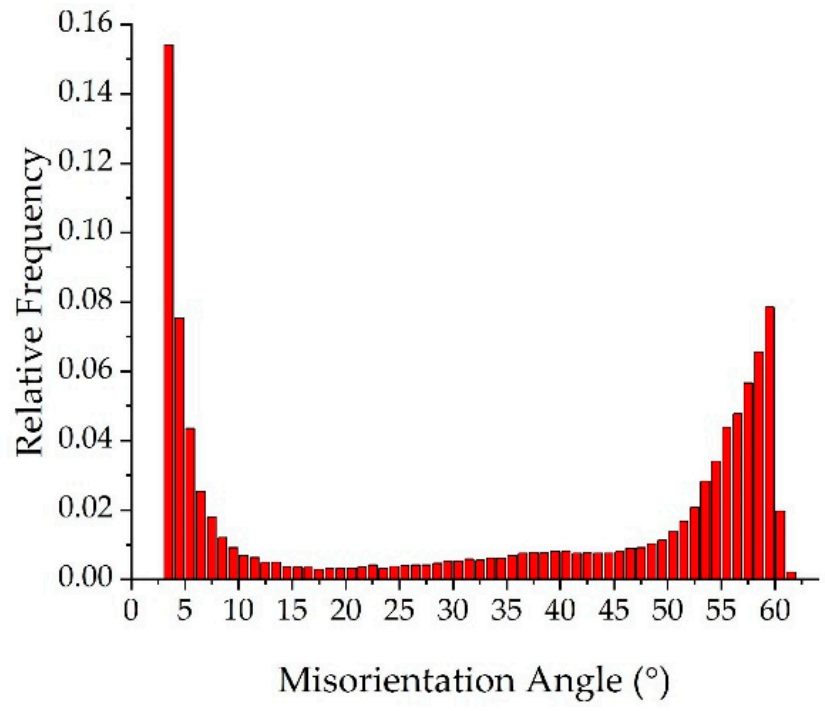

(b)

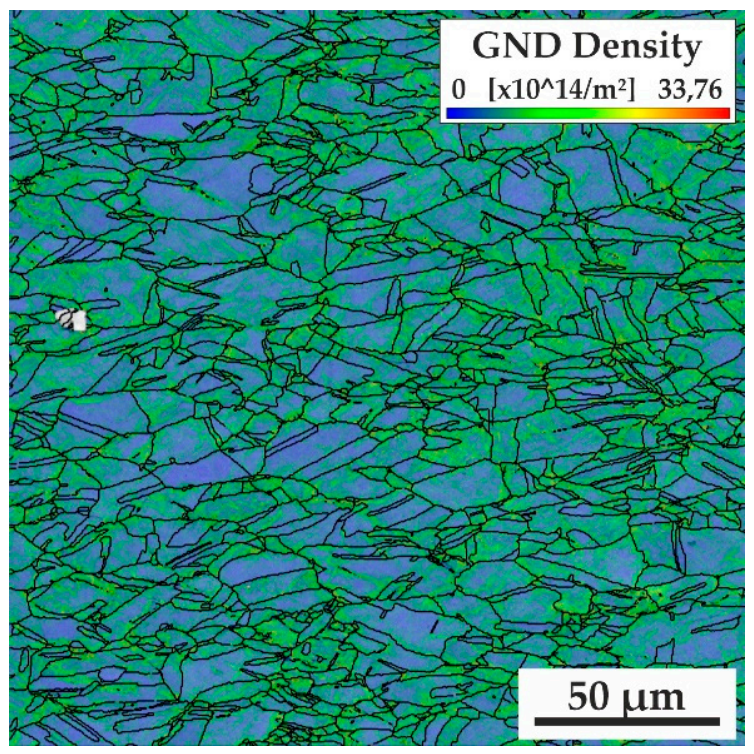

(d)

Figure 2. EBSD images after high-temperature thermo-mechanical treatment-1(HTMT-1). Orientation maps (a), grain misorientation distribution (b), phase maps with high-, low-angle and twin boundaries (c), geometrically necessary dislocations (GND) map with high-angle boundaries (d). 


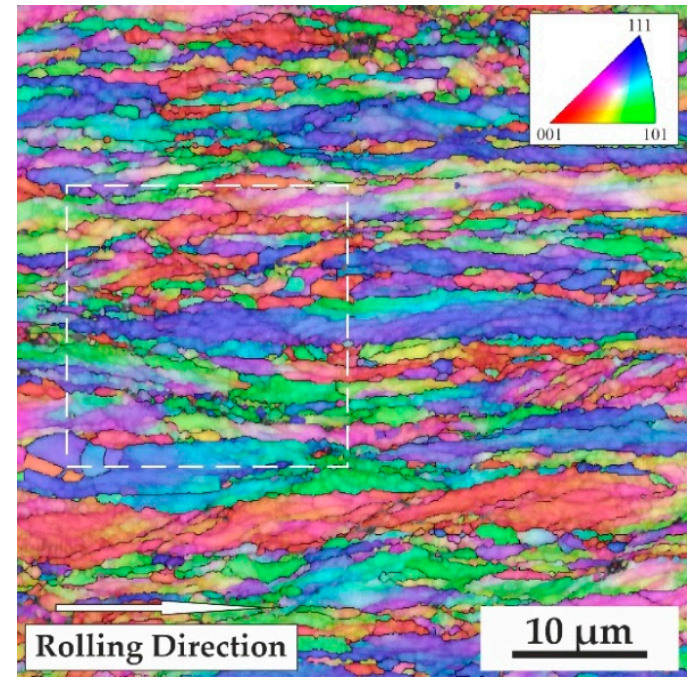

(a)

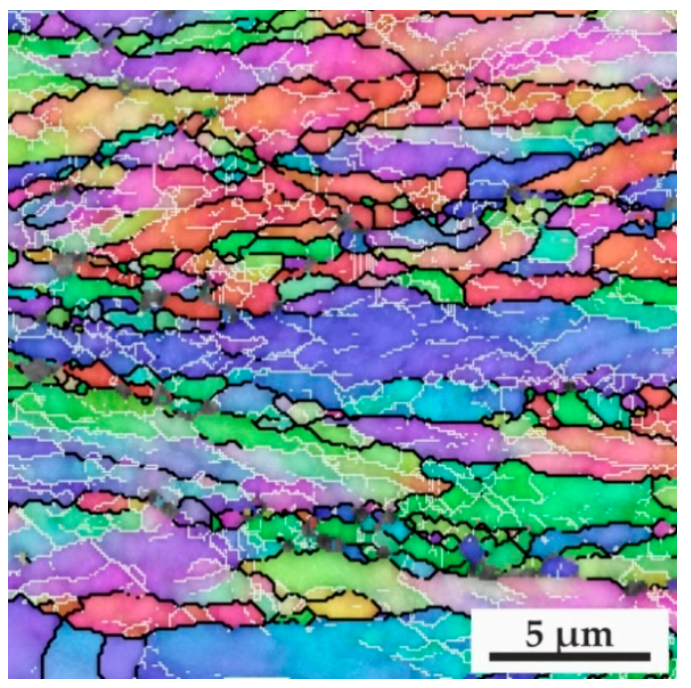

(c)

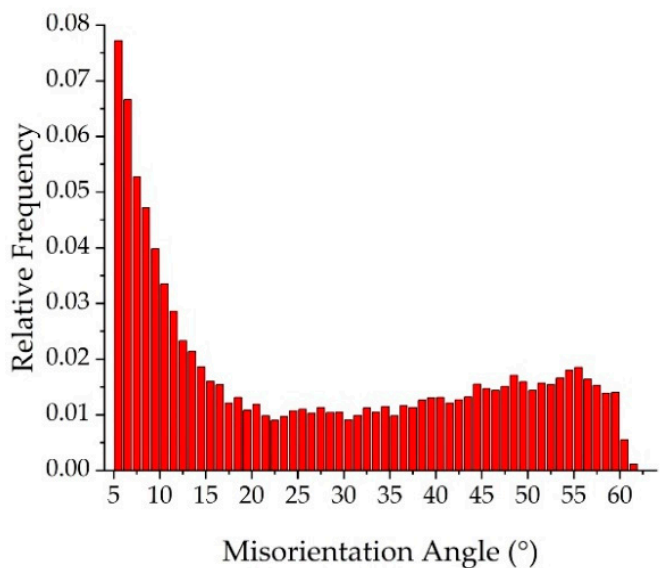

(b)

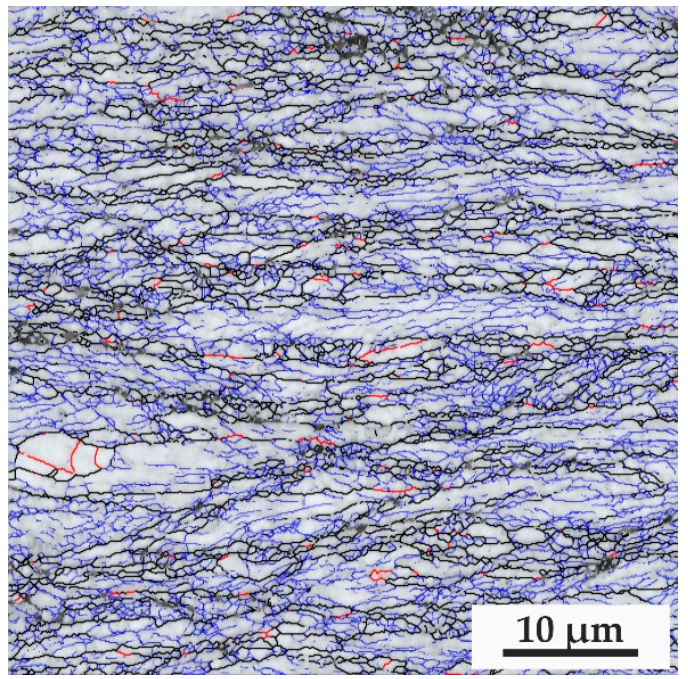

(d)

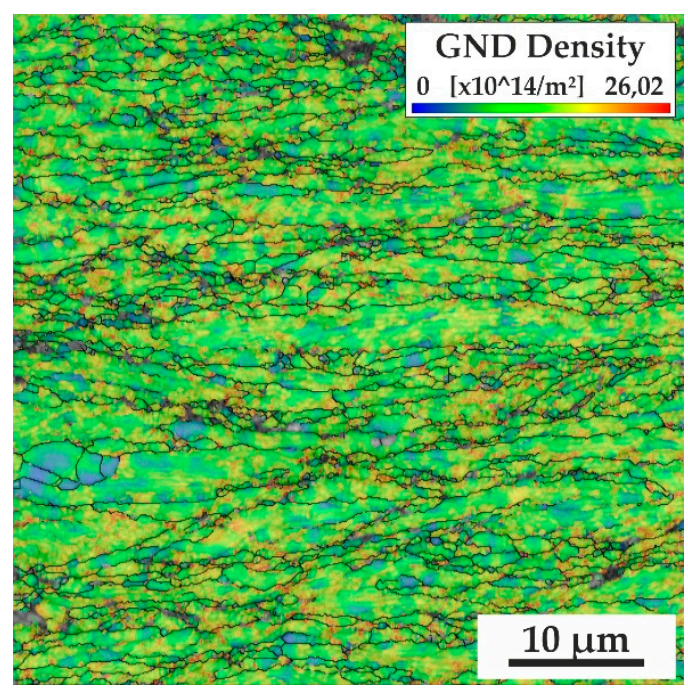

(e)

Figure 3. EBSD images after high-temperature thermo-mechanical treatment-2 (HTMT-2). Orientation maps (a), grain misorientation distribution (b), magnified selected part from image (a): orientation maps with high- and low-angle boundaries (c), phase maps with high-, low-angle, and twin boundaries (d), and GND map with high-angle boundaries (e). 
According to these data, in the initial (after quenching) state, the steel consists mainly of austenite (Figure 1). At the same time, sufficiently coarse (up to several microns) TiC particles and a small amount of the BCC phase (not shown) are detected. In some areas, its content can reach several percent. It can be the $\delta$-ferrite phase or as an artifact of strain-induced $\alpha^{\prime}$-martensite formed in the final stage of sample preparation during ion polishing. According to the EBSD analysis, in the initial state, high-angle misorientation boundaries dominate in the material and the fraction of low-angle boundaries is insignificant (Figure 1b,c). At the same time, it is necessary to note a high fraction of twin boundaries $\approx 50 \%$ (Figure $1 \mathrm{~b}, \mathrm{c}$ ). On the histogram of grain misorientation distribution, this corresponds to a narrow high peak at $60^{\circ}$. The characteristic shape and size of the twins indicate that they are annealing twins. Without taking into account the twins, the average grain size is $18 \mu \mathrm{m}$ (given the twin boundaries in the ensemble of grain boundaries, it decreases to $8 \mu \mathrm{m})$.

The grain size distribution (see Supplementary Materials Figure S2) implies that in the initial state the material has a varied-grain state: a significant fraction $(\approx 40 \%)$ of fine grains (up to $5 \mu \mathrm{m}$ ) and $\approx 15 \%$ of coarse (more than $50 \mu \mathrm{m}$ ) grains. Taking into account twins, the fraction of fine and medium $(5-15 \mu \mathrm{m})$ grains in the grain size distribution increases, while that of grains larger than $15 \mu \mathrm{m}$ decreases.

Multi-pass rolling of steel with heating to $1100{ }^{\circ} \mathrm{C}$ (HTMT-1) contributes to stretching of the initial grains in the rolling direction (Figure 2). At the same time, there are equiaxed grains, but their fraction is insignificant. The grain sizes in the rolling direction may be several times larger than those in the perpendicular direction. Many low-angle misorientation boundaries are formed in the material; their fraction is $46 \%$. (Figure $2 \mathrm{c}$ ). The fraction of twin boundaries reaches $22 \%$ (at a tolerance angle of $8^{\circ}$ ), which is less than that in the initial state. When the tolerance angle is reduced to $5^{\circ}$, this value is reduced to $16 \%$. Thus, a significant number of twin boundaries after the above processing experience deviations from the exact twin position by small angles. In the grain misorientation distribution two peaks are clearly seen, corresponding to the low-angle and twin $\left(60^{\circ}\right)$ boundaries. Both low-angle and twin boundaries lie mainly at the angles less than $30^{\circ}$ relative to the rolling direction (Figure 2c). Maps of geometrically necessary dislocations (GND) were reconstructed based on the EBSD data. It follows from the analysis of the GND map after HTMT-1 (Figure 2d) that the dislocation density inside the largest grains is rather low (less than $\left.1 \times 10^{14} \mathrm{~m}^{-2}\right)$. The areas of increased $\left(\sim 10^{15} \mathrm{~m}^{-2}\right)$ dislocation density correlate with the locations of low-angle misorientation boundaries in Figure 2c.

The actual deformation temperature was lower than the furnace temperature $\left(1100^{\circ} \mathrm{C}\right)$. However, during heating to this temperature and holding, the samples were undergoing recovery and initial stages of recrystallization, at which annealing twins were formed. During deformation, the initial annealing twins experience significant deviations from the twinning positions and become arbitrary high-angle boundaries. It is not possible to estimate which parts of the initial annealing twins were retained during deformation in three passes nor which twins were formed during heating before the last pass.

The average grain size after HTMT- 1 is $8 \mu \mathrm{m}$ (including twins $-6 \mu \mathrm{m}$ ). From the analysis of the grain size distribution after this treatment (see Supplementary Materials Figure S1), it follows that in the material, the fraction of fine (up to $5 \mu \mathrm{m}$ ) grains increases (to more than 50\%), the fraction of coarse grains decreases, and there are practically no grains larger than $50 \mu \mathrm{m}$. In this case, the shape of the distribution practically does not change relative to the initial state; the distribution itself shifts to smaller sizes. As in the case of the initial state, taking into account of twins in the distribution increases the fraction of fine and medium grains and decreases the fraction of grains larger than $15 \mu \mathrm{m}$. It should be noted that no submicron grains were found after this treatment.

Two-stage thermomechanical treatment with deformation $(e=0.8)$ with heating to $1100{ }^{\circ} \mathrm{C}$ and subsequent deformation $(e=0.7)$ with heating to $600{ }^{\circ} \mathrm{C}$ (HTMT-2) contributes to additional stretching of the initial grains in the rolling direction and their refining (Figure 3) compared to HTMT-1. 
Numerous new low-angle misorientation boundaries are formed, many of which are roughly parallel to the rolling direction (Figure 3a,d). The boundaries that are perpendicular to the rolling direction are often curved; these boundaries close the elongated fragments and form new fine equiaxed grains and subgrains (Figure 3c). However, the fraction of these boundaries in the overall structure of steel is insignificant; they are formed mainly along the grain boundaries stretched in the rolling direction. The average grain size is reduced to $1.4 \mu \mathrm{m}$. An analysis of the grain size distribution (see Supplementary Materials Figure S2) suggests that fine grains up to $3 \mu \mathrm{m}$ dominate. The fraction of coarse grains is less than $10 \%$. The distribution type is qualitatively similar to the distributions in the initial state and after HTMT-1, while the distribution itself is shifted to the fine grain sizes. The submicron grains are observed with a fraction of $\approx 50 \%$.

In the distribution of grains by misorientation the fraction of low-angle boundaries increases and reaches $\approx 60 \%$. At the same time, the fraction of twin boundaries significantly decreases, compared to the initial state and after HTMT- 1 , and is $3 \%$ at a tolerance angle of $8^{\circ}\left(1.2 \%\right.$ at a tolerance angle of $\left.5^{\circ}\right)$. The distribution itself has a pronounced peak corresponding to low-angle misorientations and a smooth increase in the fraction of boundaries with an increase in the misorientation angle to $60^{\circ}$ corresponding to twin orientations (Figure $3 b$ ).

After HTMT-2 (Figure 2d) on the GND map the dislocation density is $\sim 10^{15} \mathrm{~m}^{-2}$ in a significant part of the material. In this case, individual grains with a much lower dislocation density are also observed.

After HTMT-1 and HTMT-2, the textures are typical for warm rolling of fcc metals, namely the components: Goss- $\{110\}<001>$, A- $-\{110\}<111>$, Brass $-\{110\}<112>$, and to a lesser extent $\mathrm{Cu}-\{112\}$ [111] and S-[123] <634>. The texture is dominated by the $\alpha$-fiber $(<110>$ parallel to the normal to the rolling plane).

\subsection{TEM}

The features of microstructure of 321-type steel after initial state (ST), cold rolling, and annealing are well known and are presented in detail elsewhere [39]. It should be noted that low stacking faults energies $\left(\gamma_{\mathrm{sfe}} \leq 22 \mathrm{~mJ} / \mathrm{m}^{-2}\right)$ of steel lead to the formation of multiple stacking faults in the quenched state and annealing twins, which is confirmed by EBSD data (Figure 1).

TEM investigations have shown that under HTMT-1 the fragmentation of the grain structure with the formation of dislocation substructures and low-angle grain boundaries occurs. Figure 4 a shows an area of thin foil with a width of $\approx 2$ microns, bounded by parallel boundaries. There are rows of dislocation walls with low-angle misorientations up to $\approx 0.5^{\circ}$ and chaotically distributed dislocations in this area. The orientation of this area is close to the zone axis of [110] (Figure 4b). Figure 4c shows an area of thin foil in the left part of which there are straight plates of micro-twins with selected area electron diffraction (SAED) corresponding to the exact twin position (inset on Figure 4c). In the right part of this figure the twin boundaries are strongly curved; in the lower part of the figure, there is a bulging grain boundary. A diffraction pattern with a large selector diaphragm that captures the area of microtwins (left) and curved boundaries (right) reveals low-angle (up to $\approx 10^{\circ}$ ) azimuthal misorientation around the zone axis of [110] and a deviation of the diffraction from the exact twin position (Figure 4d). 


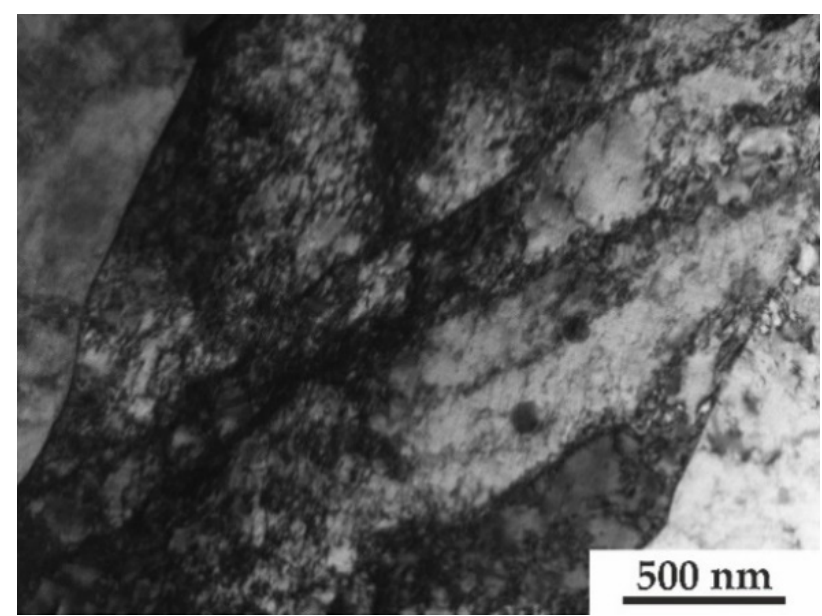

(a)

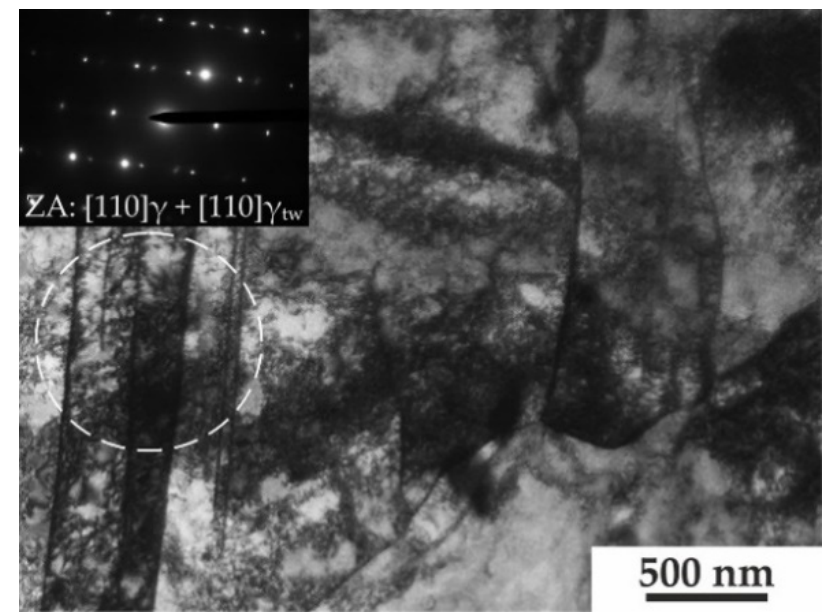

(c)

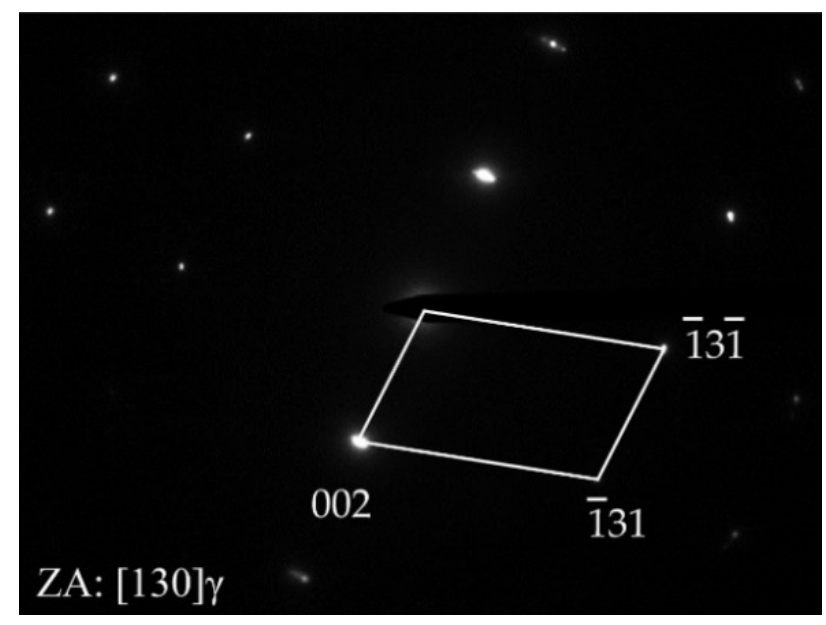

(e)

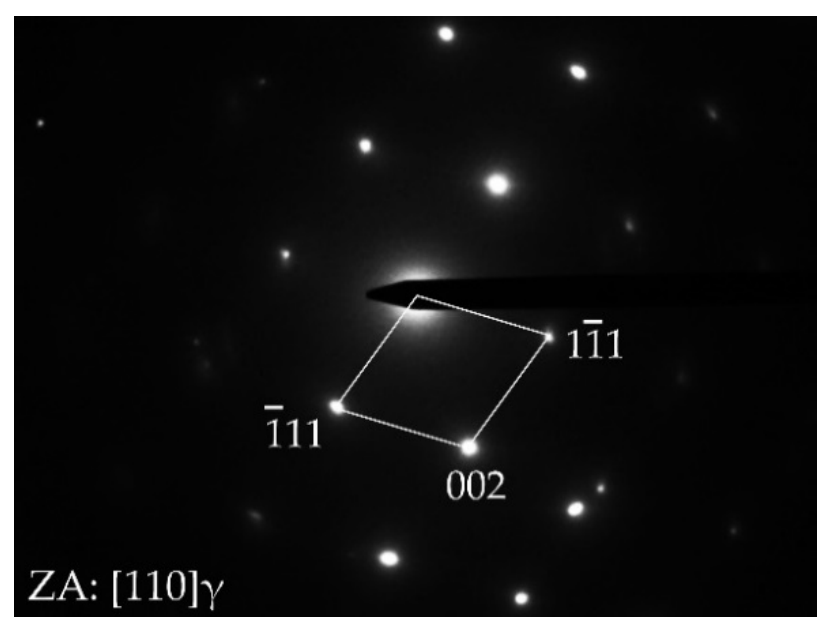

(b)

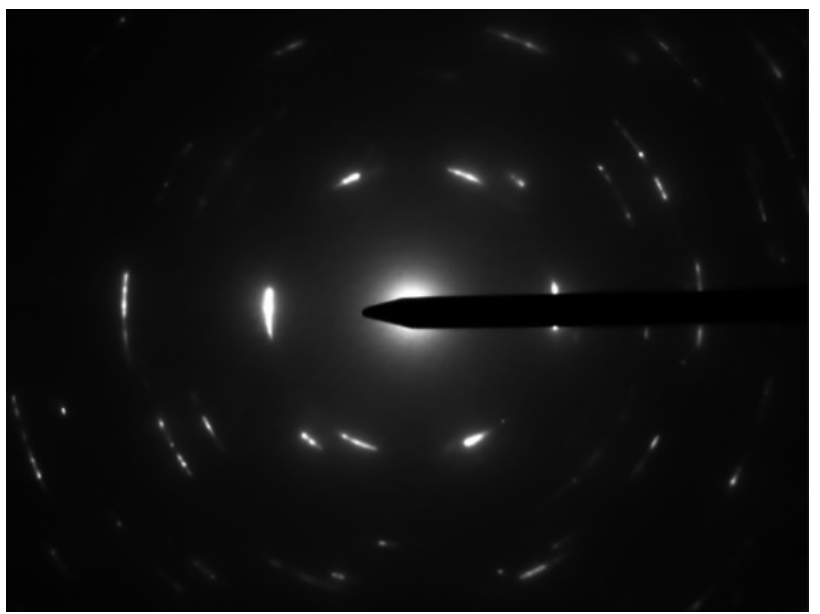

(d)

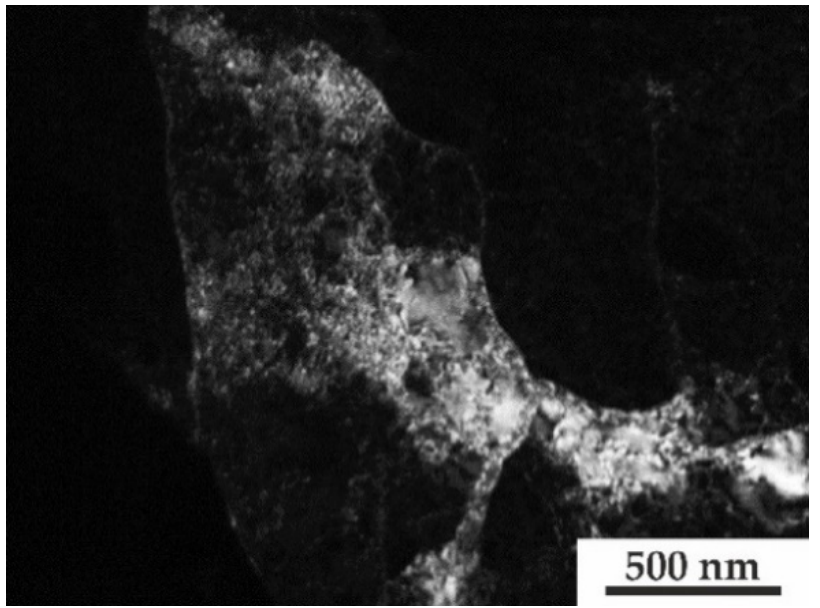

(f)

Figure 4. Cont. 


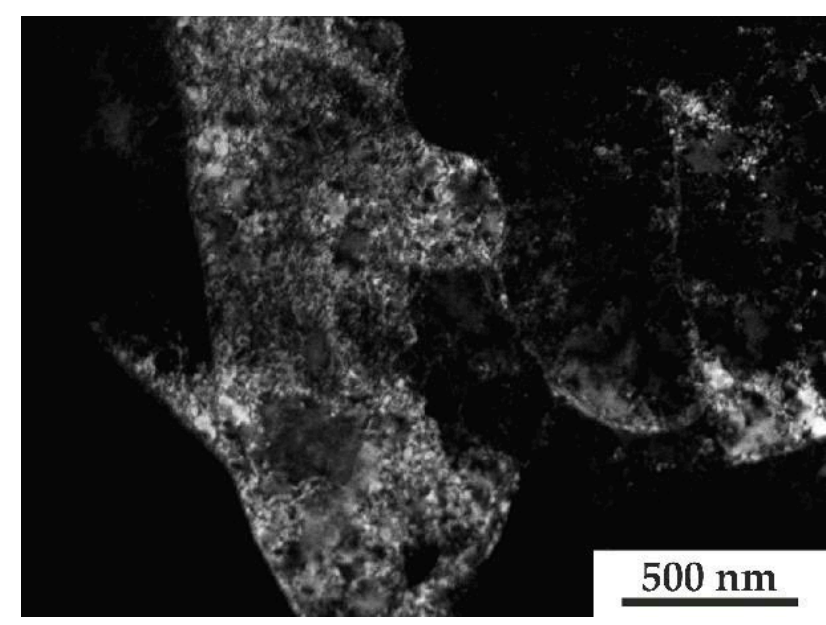

(g)

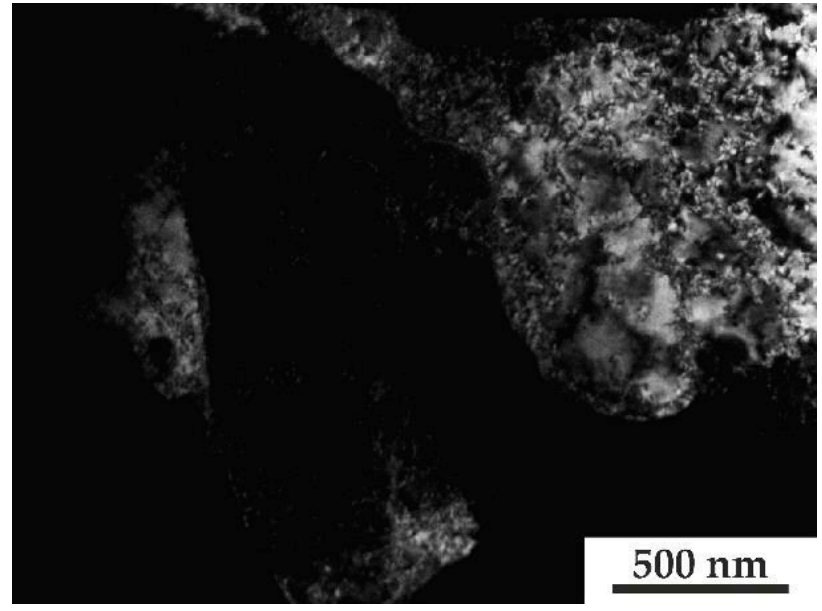

(h)

Figure 4. Transmission electron microscopy (TEM) images of steel microstructure after HTMT-1. Bright-field (BF) image (a), selected area electron diffraction (SAED) pattern (b), BF image with inset of SAED pattern from twins marked by circle (c), SAED patterns corresponding to BF image (c) with large selector diaphragm (d), SAED patterns (e), dark field (DF) images in $\mathrm{g}=002$ at the goniometer tilt angles of: $(\mathbf{f})-\left(-1^{\circ}\right),(\mathbf{g})-0^{\circ},(\mathbf{h})-\left(+1^{\circ}\right)$. The angle between projection of goniometer tilt axes and active reflection is $\approx 50^{\circ}$.

The dark-field analysis in the $\mathrm{g}=002$ reflection with a tilt of thin foil in the goniometer (Figure $4 \mathrm{f}-\mathrm{h}$ ) reveals submicron fragments with low-angle misorientation boundaries. The orientation of this region is close to the zone axis [130] (Figure 4e). Taking into account the angle $\left(\approx 50^{\circ}\right)$ between the active reflection and the projection of the goniometer tilt axis, the $1^{\circ}$ tilt in the goniometer corresponds to a change in the orientation of the dark-field image by $1^{\circ} \times \sin \left(50^{\circ}\right) \approx 0.7^{\circ}$. In other words, the misorientations of subgrain boundaries are found to be from 0.7 to $2.1^{\circ}$. Note the smooth curved shape of the sub-boundaries and the presence of almost equiaxed and elongated fragments, as well as an increased density of dislocations within the fragments (no less than $10^{14} \mathrm{~m}^{-2}$ ).

As a result of HTMT-2 the grain structure fragmentation is more intense than after HTMT-1 (Figure 5). The bright-field image (Figure 5a) shows submicron fragments with pronounced misorientation boundaries. Some boundaries are strongly curved. The shape of the fragments is nearly equiaxed. Dislocation substructures are visible inside the fragments. The density of dislocations within individual fragments reaches $10^{15} \mathrm{~m}^{-2}$. The dislocation density estimates are consistent with the data of EBSD GND maps. In SAED patterns (Figure 5b) two zone axes of [001] and [110] are detected together in a position close to the reflecting one (the zone axis of [110] is deviated from the exact reflecting position, resulting in some weak-intensity reflexes). Since the angle between these crystallographic directions in cubic crystals is at least $45^{\circ}$, high-angle misorientation boundaries are present in the area under consideration. In addition to high-angle misorientation boundaries, low-angle azimuthal misorientations are observed on the SAED pattern.

In addition to almost equiaxed fragments, there are elongated lamellar fragments with a width of $100-300 \mathrm{~nm}$ in the steel structure, Figure $5 \mathrm{c}$. The orientation of these lamellar microstructures on SAED patterns is close to the zone axis of [112] (Figure 5d). Weak reflections located near the bright reflections $g=-200$ and $g=11-1$ of this zone axis indicate the presence of low-angle azimuthal misorientations. Nanoscale TiC particles are also found in this structure. 


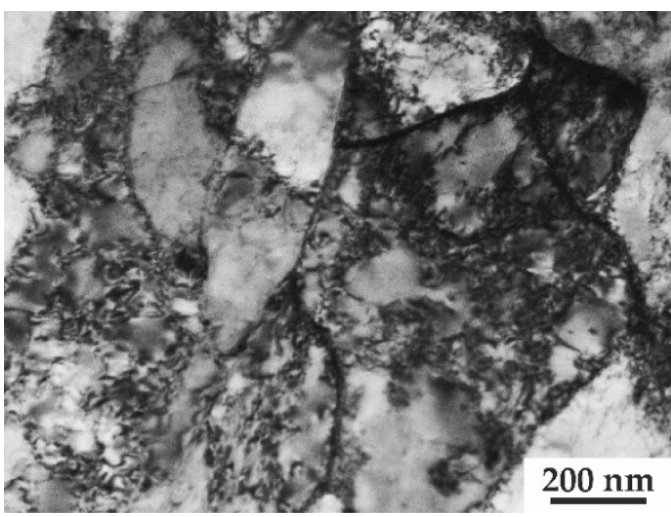

(a)

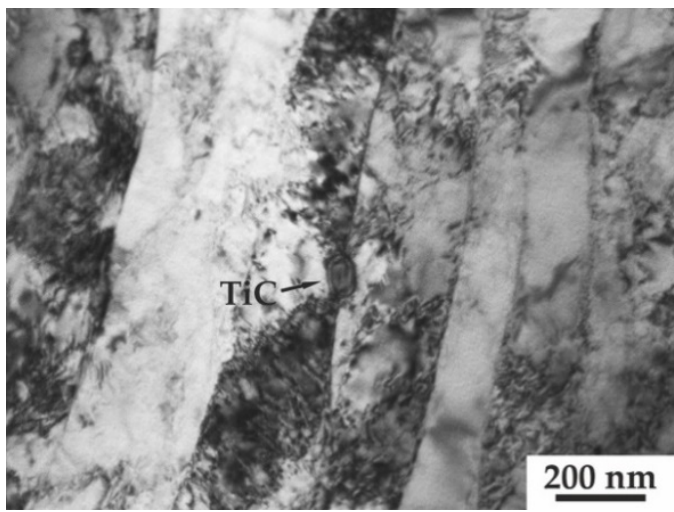

(c)

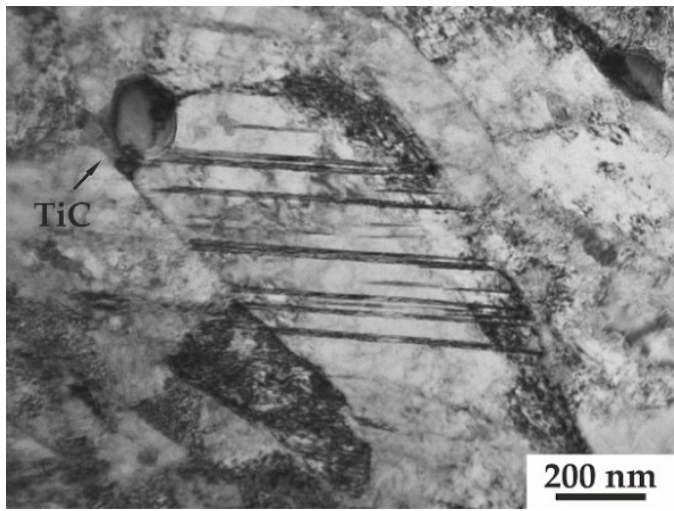

(e)

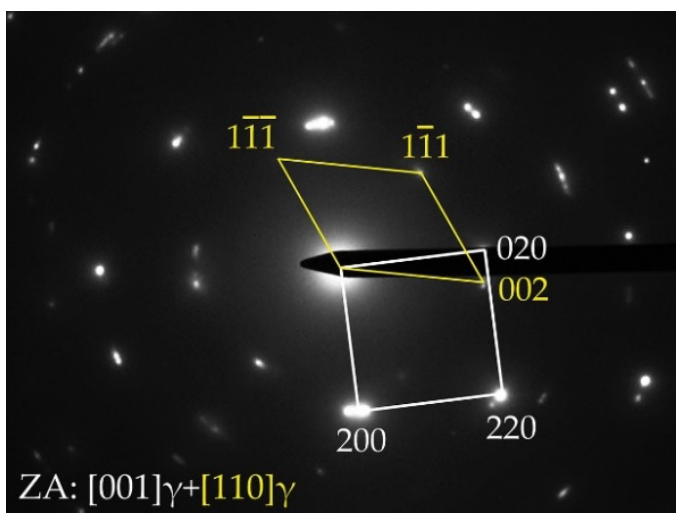

(b)

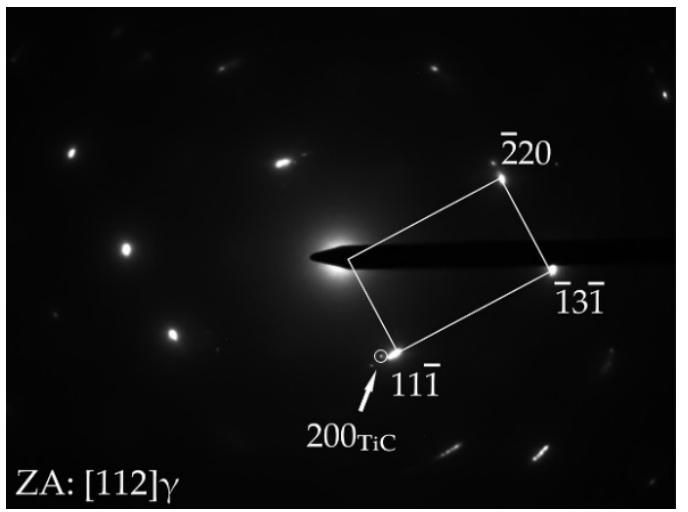

(d)

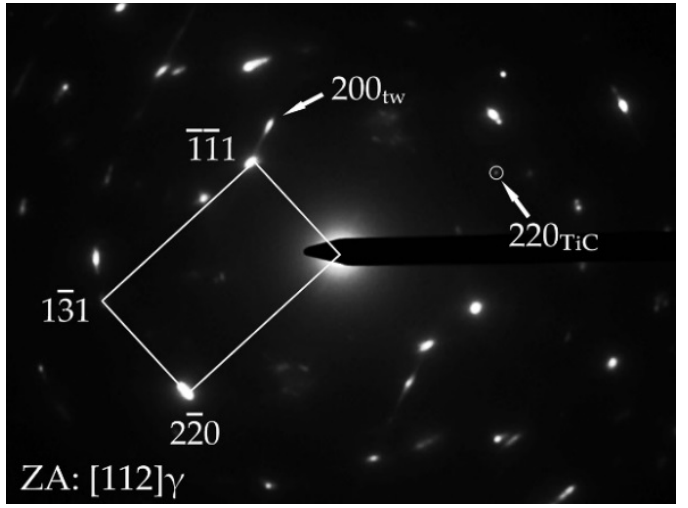

(f)

Figure 5. TEM images of steel microstructure after HTMT-2. BF image of nearly-equiaxed microstructure (a), corresponding SAED patterns (b), BF image of lamellar microstructure (c), corresponding SAED patterns (d), BF image of submicron fragment with nanotwins (e), corresponding SAED patterns (f).

In addition to these structural features, some submicron grains exhibit thin plates of nanotwins (Figure 5e). In this figure, nanotwins are detected near a $\mathrm{TiC}$ particle of about $100 \mathrm{~nm}$ in size. It is assumed that this non-deformable particle plays the role of a stress concentrator under high-temperature deformation. In this case the deformation nanotwins could have been formed during the relaxation of internal stresses. In SAED patterns (Figure 5f), in addition to reflections from the zone axis of [112], there are reflections belonging to other zone axes, twin reflections with a characteristic extension due to the small thickness of the nanotwins, and reflections of the $\mathrm{TiC}$ particles. 


\subsection{Mechanical Properties}

The results of the studies of mechanical properties of steel obtained during tensile tests of the samples in the initial (ST) state and after HTMT- 1 and HTMT-2 treatments are presented in Figure 6 and Table 1 . The data imply that HTMT- 1 results in an $\approx 1.7$ yield strength increase of steel, while the tensile strength increases by $\approx 1.3$ times compared to the initial state. The elongation-to-failure reaches $26 \%$, which is 1.5 times lower than in the initial state. Based on the above studies of the structural features of steel by the EBSD and TEM methods, its mechanical properties are determined by a decrease (relative to the initial state) in the average grain size down to $8 \mu \mathrm{m}$ and a formation of preferentially low-angle misorientation boundaries ( $46 \%$ of all boundaries) and dislocation substructures during processing.

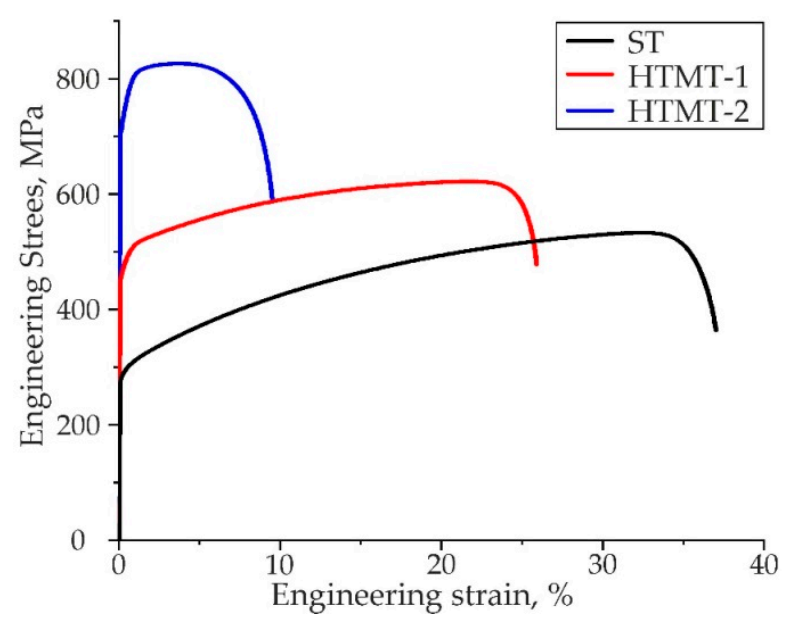

Figure 6. Engineering stress-engineering strain curves of some of the treated steel samples.

Table 1. Mechanical Properties of AISI 321-type Steel.

\begin{tabular}{cccc}
\hline Treatment & Yield Strength, MPa & Tensile Strength, MPa & Elongation to Failure, $\%$ \\
\hline ST & $272 \pm 11$ & $554 \pm 26$ & $39 \pm 3$ \\
HTMT-1 & $477 \pm 38$ & $637 \pm 41$ & $26 \pm 7$ \\
HTMT-2 & $677 \pm 34$ & $793 \pm 34$ & $12 \pm 6$ \\
\hline
\end{tabular}

After HTMT-2, the yield strength increases by a factor of 2.5, and the ultimate strength increases by a factor of 1.4 relative to the initial state. In this case, the elongation to failure decreases to $12 \%$, which is $\approx 3$ times lower than in the initial state. According to the results of structural investigations, the average grain size resulting from HTMT-2 reaches down to $1.4 \mu \mathrm{m}$; the structure contains numerous low-angle misorientation boundaries ( $60 \%$ of all boundaries) and an increased dislocation density. It should be noted, however, that the grains (and subgrains) after these treatments are mainly elongated in the rolling direction. Small equiaxed grains are formed, but they are much fewer than elongated grains (Figure 3).

\section{Discussion}

Based on the results of the microstructure and mechanical properties studies, it was found that grain refinement with the formation of an elongated grain-subgrain structure with a high fraction of low-angle boundaries provides an increase in the strength of the 321-type steel relative to ST values. After HTMT-2, the average grain size is finer and the structure is more defective than after HTMT-1, in which a significant $(25 \%)$ fraction of twin boundaries is found. These twins are formed during annealing at $1100{ }^{\circ} \mathrm{C}$ before rolling, which is confirmed by the high (50\%) fraction of twin boundaries in the ST state. A significant number of twin boundaries in metastable austenitic steels was also observed 
by EBSD method $[25,37,40]$ in ST and hot deformed states. Deformation at $600{ }^{\circ} \mathrm{C}$ almost completely destroys the annealing twins; as a result, the fraction of twin boundaries decreases to $3 \%$. A significant number of high-angle boundaries after thermomechanical treatments have small (several degrees) deviations from the exact twin position. This occurs as a result of the incorporation of gliding dislocations into twin boundaries.

It should be noted that the main deformation mechanism under above treatments is dislocation slip (including cross slip or / and climb). It provides for the formation of multiple sub-boundaries within the grains, the elongation of the original grains along the rolling direction, and the deviation of the twin boundaries from the exact position. As a result, the fraction of low-angle boundaries in the distribution of boundaries by misorientations reaches $46 \%$ after HTMT- 1 and $60 \%$ after HTMT-2. The detected thin nanotwins are likely to form as a result of local stress relaxation from concentrators (for example, TiC particles) after treatment. The formation of geometrically necessary dislocations also takes place in the process of the studied treatments. The used degrees and temperatures of deformation do not provide a transition from preferentially low-angle deformation misorientation boundaries to high-angle ones, which is clearly seen in the distribution of grain boundaries by misorientations (Figures 3 and 4 ).

The deformation temperatures used in this work prevent intense precipitation of $\mathrm{TiC}$ and $\mathrm{M}_{23} \mathrm{C}_{6}$ particles, which can form under conditions of hot deformation of type 321 steel in the temperature range of $750-850{ }^{\circ} \mathrm{C}[36,37]$.

The results obtained confirm the previously identified main regularities of the microstructure formation in series 300 austenitic steels under hot deformation conditions. In [30-32], using thermomechanical control processing, it is shown that deformation above the recrystallization start temperature leads to a slight decrease in the grain size and an increase in the yield strength relative to ST by 50-100 MPa at good values of elongation. As the rolling end temperature decreases below the recrystallization start temperature, a deformed structure is formed which is elongated in the rolling direction. This leads to the formation of a well-developed substructure, a significant increase in the yield strength, and a corresponding decrease in the elongation. A decrease in the temperature and an increase in the degree of deformation are limited by a significant increase in the rolling load [32].

In the HTMT- 1 and HTMT-2 mode, the temperature of hot and warm rolling was determined by the furnace temperature and the time of the sample transfer to the rolling mill (without heating the rolls), in contrast to thermomechanical control processing [32]. Therefore, in our case the actual rolling end temperature was lower than the furnace temperature. It should also be noted that after each pass, the samples were quenched in water. These differences in the processing conditions determine the features of the resulting structural states and the mechanical properties of steel 321. The formation of a well-developed substructure (Figures 2 and 4) in steel 321 after HTMT-1 makes an additional contribution to strengthening compared to typical values [32] of the yield strength of austenitic steels after hot deformation above the recrystallization start temperatures. The new processing scheme (HTMT-2), combining deformation in the recrystallization region with warm deformation at a relatively low $\left(600^{\circ} \mathrm{C}\right)$ temperature, is aimed at further increasing the density of defects, including sub-boundaries. The formation of these microstructure features is confirmed in detail by the EBSD and TEM methods (Figures 2-5).

In this work, the strengthening of metastable austenitic steel of 321-type under conditions of hot and warm deformation is achieved due to fine grains elongated in the rolling direction, high density of submicron subgrains, and dislocations. Moreover, there are too few defect-free grains in the steel structure, the formation of which contributes to an increase in the ductility of steels. The specified features of the microstructure of steel lead to weaker strengthening compared to the equiaxed fine-grained structure with similar grain sizes as in $[28,29,41]$. In these works the conditions of dynamic recrystallization in the process of hot and warm plastic deformation of austenitic steels were achieved by a higher strain $(e \geq 2)$ with the corresponding choice of temperature-rate treatment modes. To sum up, in this work we have observed the initial stages of recrystallization only. For 
HTMT-2, some recrystallized grains can appear in the first stage of deformation at $1100{ }^{\circ} \mathrm{C}$ and persist during the subsequent deformation at lower temperatures.

\section{Conclusions}

In this work, for the first time, the microstructure and mechanical properties of 321type steel have been studied in detail after a combination of the deformation above the recrystallization start temperature and significantly below this temperature. It has been shown that multiple rolling of AISI 321 steel with heating to $1100{ }^{\circ} \mathrm{C}$ with a moderate strain of $e=1.6$ leads to a decrease in the average grain size (down to $8 \mu \mathrm{m}$ ), elongation of the initial grains in the rolling direction and the formation of preferentially low-angle misorientation boundaries $(46 \%)$ and twin $(25 \%)$ boundaries. These features of the microstructure lead to increase (by a factor of 1.7) in the yield strength relative to the initial state and high values of the elongation-to-failure $(26 \%)$. The combination of deformation with heating to $1100{ }^{\circ} \mathrm{C}$ $(e=0.8)$ and subsequent deformation with heating to $600{ }^{\circ} \mathrm{C}(e=0.7)$ provides a decrease in the average grain size down to $1.4 \mu \mathrm{m}$. Grains and subgrains after this treatment are more elongated in the rolling direction; the fraction of low-angle misorientation boundaries increases and reaches $60 \%$, while the fraction of twin boundaries decreases to $3 \%$, compared to the first treatment. In grains and subgrains, an increased dislocation density is observed $\left(10^{14}-10^{15} \mathrm{~m}^{-2}\right)$. The yield strength after this treatment increases by a factor of about 2.5 relative to the initial values at a ductility of $12 \%$. The main deformation mechanism under the above treatments is dislocation slip (including cross slip or/and climb).

Supplementary Materials: The following are available online at https: / www.mdpi.com/article / 10.3390/met11040645/s1, Figure S1: The scheme of sample cutting for microstructure observation and tension tests; Figure S2: Histograms of grain size distribution with $(a, c, e)$ and without $(b, d)$ twin boundaries after: ST (a,b), HTMT-1 (c,d) and HTMT-2 (e).

Author Contributions: Conceptualization, I.L. and S.A.; methodology, I.L.; formal analysis, E.M.; investigation, S.A., K.A., and E.M.; writing-original draft preparation, I.L.; writing-review and editing, N.P. and I.L.; visualization, S.A. and E.M.; supervision, I.L.; project administration, I.L. All authors have read and agreed to the published version of the manuscript.

Funding: The work was performed according to the Government Research Assignment for the Institute of Strength Physics and Materials Science of the Siberian Branch of the Russian Academy of Sciences (ISPMS SB RAS), project No. FWRW-2021-0008.

Institutional Review Board Statement: Not applicable.

Informed Consent Statement: Not applicable.

Data Availability Statement: Data is contained within the article or Supplementary Material.

Acknowledgments: The investigations have been carried out using the equipment of the Tomsk Materials Research Share Use Centre and the equipment of Share Use Centre "Analytical Center for Geochemistry of Natural Systems" of Tomsk State University.

Conflicts of Interest: The authors declare no conflict of interest.

\section{References}

1. Hedayati, A.; Najafizadeh, A.; Kermanpur, A.; Forouzan, F. The effect of cold rolling regime on microstructure and mechanical properties of AISI 304L stainless steel. J. Mater. Process. Technol. 2010, 210, 1017-1022. [CrossRef]

2. Mallick, P.; Tewary, N.K.; Ghosh, S.K.; Chattopadhyay, P.P. Effect of cryogenic deformation on microstructure and mechanical properties of 304 austenitic stainless steel. Mater. Charact. 2017, 133, 77-86. [CrossRef]

3. Rybalchenko, O.V.; Anisimova, N.Y.; Kiselevsky, M.V.; Belyakov, A.N.; Tokar, A.A.; Terent'ev, V.F.; Prosvirnin, D.V.; Rybalchenko, G.V.; Raab, G.I.; Dobatkin, S.V. The influence of ultrafine-grained structure on the mechanical properties and biocompatibility of austenitic stainless steels. J. Biomed. Mater. Res. 2020, 108, 1460-1468. [CrossRef] [PubMed]

4. Zhao, J.; Jiang, Z. Thermomechanical processing of advanced high strength steels. Prog. Mater. Sci. 2018, 94, 174-242. [CrossRef]

5. Eskandari, M.; Najafizadeh, A.; Kermanpur, A. Effect of strain-induced martensite on the formation of nanocrystalline 316L stainless steel after cold rolling and annealing. Mat. Sci. Eng. A 2009, 519, 46-50. [CrossRef] 
6. Odnobokova, M.; Belykov, A.; Enikeev, N.; Molodov, D.A.; Kaibyshev, R. Annealing behavior of a 304L stainless steel processed by large strain cold and warm rolling. Mater. Sci. Eng. A 2017, 689, 370-383. [CrossRef]

7. Rajasekhara, S.; Karjalainen, L.P.; Kyröläinen, A.; Ferreira, P.J. Microstructure evolution in nano/submicron grained AISI 301LN stainless steel. Mater. Sci. Eng. A 2010, 527, 1986-1996. [CrossRef]

8. Chen, J.; Zhang, Y.; Ge, J.; Peng, H.; Huang, S.; Yang, Q.; Wen, Y. Effect of thermomechanical cycling on martensitic transformation and shape memory effect in 304 austenitic steel. Metals 2020, 10, 901. [CrossRef]

9. Kaoumi, D.; Liu, J. Deformation induced martensitic transformation in 304 austenitic stainless steel: In-situ vs. ex-situ transformation electron microscopy characterization. Mater. Sci. Eng. A 2018, 715, 73-82. [CrossRef]

10. Mallick, P.; Tewary, N.K.; Ghosh, S.K.; Chattopadhyay, P.P. Microstructure-tensile property correlation in 304 stainless steel after cold deformation and austenite reversion. Mater. Sci. Eng. A 2017, 707, 488-500. [CrossRef]

11. Litovchenko, I.Y.; Akkuzin, S.A.; Polekhina, N.A.; Tyumentsev, A.N.; Naiden, E.P. The features of microstructure and mechanical properties of metastable austenitic steel subjected to low-temperature and subsequent warm deformation. Russ. Phys. J. 2016, 59, 782-787. [CrossRef]

12. Torganchuk, V.; Belyakov, A.; Kaibyshev, R. Effect of rolling temperature on microstructure and mechanical properties of $18 \% \mathrm{Mn}$ TWIP/TRIP steels. Mater. Sci. Eng. A 2017, 708, 110-117. [CrossRef]

13. Yan, F.K.; Liu, G.Z.; Tao, N.R.; Lu, K. Strength and ductility of 316 austenitic stainless steel strengthened by nano-scale twin bundles. Acta Mater. 2012, 60, 1059-1071. [CrossRef]

14. Akkuzin, S.A.; Litovchenko, I.Y.; Tyumentsev, A.N.; Chernov, V.M. Microstructure and mechanical properties of austenitic steel EK-164 after thermomechanical treatments. Russ. Phys. J. 2019, 62, 698-704. [CrossRef]

15. Akkuzin, S.A.; Litovchenko, I.Y. The influence of deformation and short-term high-temperature annealing on the microstructure and mechanical properties of austenitic steel 17Cr-14Ni-3Mo (316 type). Russ. Phys. J. 2019, 62, 1511-1517. [CrossRef]

16. Shen, Y.F.; Li, X.X.; Sun, X.; Wang, Y.D.; Zuo, L. Twinning and martensite in a 304 austenitic stainless steel. Mater. Sci. Eng. A 2012, 552, 514-522. [CrossRef]

17. Gong, N.; Wu, H.B.; Niu, G.; Cao, J.M.; Zhang, D. Effect of martensitic transformation on nano/ultrafine-grained structure in 304 austenitic stainless steel. J. Iron Steel Res. Int. 2017, 24, 1231-1237. [CrossRef]

18. Mumtaz, K.; Takahashi, S.; Echigoya, J.; Kamada, Y.; Zhang, L.F.; Kikuchi, H.; Ara, K.; Sato, M. Magnetic measurements of martensitic transformation in austenitic stainless steel after room temperature rolling. J. Mater. Sci. 2004, 39, 85-97. [CrossRef]

19. Rezaee, A.; Najafizadeh, A.; Kermanpur, A.; Moallemi, M. The influence of reversion annealing behavior on the formation of nanograined structure in AISI 201L austenitic stainless steel through martensite treatment. Mat. Des. 2011, 32, 4437-4442. [CrossRef]

20. Misra, R.D.K.; Nayak, S.; Venkatasurya, P.K.C.; Ramuni, V.; Somani, M.C.; Karjalainen, L.P. Nanograined/ultrafine-grained structure and tensile deformation behavior of shear phase reversion-induced 301 austenitic stainless steel. Metall. Mater. Trans. A 2010, 41, 2164-2174. [CrossRef]

21. Järvenpää, A.; Jaskari, M.; Kisko, A.; Karjalainen, P. Processing and properties of reversion-treated austenitic stainless steels. Metals 2020, 10, 281. [CrossRef]

22. El Wahabi, M.; Gavard, L.; Montheillet, F.; Cabrera, J.M.; Prado, J.M. Effect of initial grain size on dynamic recrystallization in high purity austenitic stainless steels. Acta Mater. 2005, 53, 4605-4612. [CrossRef]

23. Belyakov, A.; Sakai, T.; Miura, H.; Kaibyshev, R. Substructures and internal stresses developed under warm severe deformation of austenitic stainless steel. Scr. Mater. 2000, 42, 319-325. [CrossRef]

24. Sun, H.; Sun, Y.; Zhang, R.; Wang, M.; Tang, R.; Zhou, Z. Hot deformation behavior and microstructural evolution of a modified 310 austenitic steel. Mater. Des. 2014, 64, 374-380. [CrossRef]

25. Tikhonova, M.; Kaibyshev, R.; Fang, X.; Wang, W.; Belyakov, A. Grain boundary assembles developed in an austenitic stainless steel during large strain warm working. Mater. Charact. 2012, 70, 14-20. [CrossRef]

26. Behjati, P.; Kermanpur, A.; Najafizadeh, A.; Baghbadorani, H.S. Microstructural investigation on deformation behavior of high purity Fe-Cr-Ni austenitic alloys during tensile testing at different temperatures. Mater. Sci. Eng. A 2014, 618, 16-21. [CrossRef]

27. Galindo-Nava, E.I.; Rivera-Díaz-del-Castillo, P.E.J. Understanding martensite and twin formation in austenitic steels: A model describing TRIP and TWIP effects. Acta Mater. 2017, 128, 120-134. [CrossRef]

28. Odnobokova, M.; Yanushkevich, Z.; Kaibyshev, R. On the strength of a 316L-type stainless steel subjected to cold or warm rolling followed by annealing. Materials 2020, 13, 2116. [CrossRef]

29. Tikhonova, M.; Belyakov, A.; Kaibyshev, R. Strain-induced grain evolution in an austenitic stainless steel under warm multiple forging. Mater. Sci. Eng. A 2013, 564, 413-422. [CrossRef]

30. Yamamoto, S.; Sakiyama, T.; Ouchi, C. Effect of alloying elements on recrystallization kinetics after hot deformation in austenitic stainless steels. Trans. ISIJ 1987, 27, 446-452. [CrossRef]

31. Ikeda, S.; Tone, S.; Takashima, S.; Kaji, H. Effect of thermo-mechanical control process on strengthening of a $22 \mathrm{Mn}-13 \mathrm{Cr}-5 \mathrm{Ni}$ austenitic stainless process on strengthening of steel plate for cryogenic use. ISIJ Int. 1990, 30, 600-607. [CrossRef]

32. Ouchi, C. Development of steel plates by intensive use of TMCP and direct quenching processes. ISIJ Int. 2001, 41, 542-553. [CrossRef]

33. Mataya, M.; Brown, E.; Riendeau, M. Effect of hot working on structure and strength of type 304L austenitic stainless steel. Metall. Trans. A 1990, 21A, 1969-1987. [CrossRef] 
34. Ghazani, M.; Eghbali, B.; Ebrahimi, G. Kinetics and critical conditions for initiation of dynamic recrystallization during hot compression deformation of AISI 321 austenitic stainless steel. Met. Mater. Int. 2017, 23, 964-973. [CrossRef]

35. Ghazani, M.; Eghbali, B. Prediction of post-deformation recrystallization kinetics in AISI 321 austenitic stainless steel using double-stage hot compression. J. Mater. Eng. Perform. 2019, 28, 3567-3575. [CrossRef]

36. Havela, L.; Kratochvíl, P.; Lukáč, P.; Smola, B.; Svobodová, A. Softening during and after the hot deformation of the AISI 321 steel with respect to practical applications. Czech. J. Phys. B 1988, 38, 384-388. [CrossRef]

37. Ghazani, M.S.; Eghbali, B. Characterization of the hot deformation microstructure of AISI 321 austenitic stainless steel. Mater. Sci. Eng. A 2018, 730, 380-390. [CrossRef]

38. Hirsh, P.B.; Howie, A.; Nicholson, R.B.; Pashley, D.W.; Whelan, M.J. Electron. Microscopy of Thin Crystals; Butterworths: London, UK, 1965; p. 549.

39. Astafurov, S.V.; Maier, G.G.; Melnikov, E.V.; Moskvina, V.A.; Panchenko, M.Y.; Astafurova, E.G. The strain-rate dependence of the Hall-Petch effect in two austenitic stainless steels with different stacking fault energies. Mater. Sci. Eng. A 2019, 756, 365-372. [CrossRef]

40. Mirzadeh, H.; Cabrera, J.M.; Najafizadeh, A.; Calvillo, P.R. EBSD study of a hot deformed austenitic stainless steel. Mater. Sci. Eng. A 2012, 538, 236-245. [CrossRef]

41. Yanushkevich, Z.; Lugovskaya, A.; Belyakov, A.; Kaibyshev, R. Deformation microstructures and tensile properties of an austenitic stainless steel subjected to multiple warm rolling. Mater. Sci. Eng. A 2016, 667, 279-285. [CrossRef] 